\title{
Does Uncertainty Moderate the Relationship between Strategic Flexibility and Companies' Performance? Evidence from Small and Medium Pharmaceutical Companies in Iran
}

\author{
Allam Yousuf ${ }^{1} \mathbb{C}$, Vahid Zeynvand Lorestani ${ }^{2}$, Judit Oláh ${ }^{1,3, * \mathbb{C}}$ and János Felföldi ${ }^{1}$ \\ 1 Institute of Applied Informatics and Logistics, Faculty of Economics and Business, University of Debrecen, \\ 4032 Debrecen, Hungary; allam.yousuf@econ.unideb.hu (A.Y.); felfoldi.janos@econ.unideb.hu (J.F.) \\ 2 Ihrig Károly Doctoral School, University of Debrecen, 4032 Debrecen, Hungary; \\ vahid.zeynvand@econ.unideb.hu \\ 3 College of Business and Economics, University of Johannesburg, Johannesburg 2006, South Africa \\ * Correspondence: olah.judit@econ.unideb.hu; Tel.: +36-20-286-9085
}

\section{check for}

updates

Citation: Yousuf, A.; Lorestani, V.Z.; Oláh, J.; Felföldi, J. Does Uncertainty Moderate the Relationship between Strategic Flexibility and Companies' Performance? Evidence from Small and Medium Pharmaceutical Companies in Iran. Sustainability 2021 13, 9157. https://doi.org/10.3390/ su13169157

Academic Editors: Heesang Lee, Juneseuk Shin and Heedong Yang

Received: 4 July 2021

Accepted: 13 August 2021

Published: 16 August 2021

Publisher's Note: MDPI stays neutral with regard to jurisdictional claims in published maps and institutional affiliations.

Copyright: (c) 2021 by the authors. Licensee MDPI, Basel, Switzerland. This article is an open access article distributed under the terms and conditions of the Creative Commons Attribution (CC BY) license (https:// creativecommons.org/licenses/by/ $4.0 /)$.

\begin{abstract}
The business environment has become complicated-full of risk and uncertainty over and above companies' control - therefore companies must find mechanisms to enhance their performance in the light of this instability. The Iranian market is one of the best examples of unstable markets because of its political and economic circumstances; despite this, the pharmaceutical industry in Iran is considered one of the best industries, which is still working efficiently. The aim of the study is to investigate the impact of strategic flexibility on the performance of Iranian SME pharmaceutical companies, by considering the effect of environmental uncertainty as a moderator. The study is a cross-sectional one. Primary data was collected from 113 companies by using an adopted questionnaire. The questionnaires were forwarded to managers at these companies, a purposive (selective) sampling technique was used to collect the data, and the total number of responses that were valid for statistical analysis was 228 . The response rate was $67.25 \%$. The results showed that strategic flexibility positively affects companies' performance. Supply and demand uncertainty moderate the relationship between strategic flexibility and companies' performance.
\end{abstract}

Keywords: resource flexibility; coordination flexibility; supply uncertainty; demand uncertainty; financial performance; customer satisfaction; operational performance

\section{Introduction}

Performance and uncertainty have been strongly present in management and economics literature [1]. DiFonzo mentioned that uncertainty cannot be accurately understood because it is a result of unforeseen circumstances, but it is possible to reduce environmental uncertainty by taking strategic actions that lead to higher levels of company performance [2]. Here, we can refer to flexibility at the strategic level as one of those strategic actions. Moreover, environmental uncertainty as a result of a lack of familiarity with new markets is considered a serious threat to companies' survival because of their inability to predict or control environmental changes which affect companies' ability to acquire the required resources for continued production [3]. Thus companies should find a relevant way to deal with uncertainty in dynamic environments.

Flexibility is a measure that shows how prepared an organization is to respond and adapt to changes in the environment [4]. Sáenz mentioned that flexibility is an important mechanism, especially in dynamic environments, where the needs and preferences of customers are changing continuously [5]. And as a competency, it helps companies to enhance their performance [6]. Moreover, flexibility is considered a critical capability that enables companies to achieve good performance by improving their ability to respond to changes quickly [7]. 
Furthermore, flexibility as a strategic technique serves in the promotion of companies' competitiveness in an unstable business environment [8]. Despite this, there is no specific definition for flexibility because it can be used in different contexts [9]. As a result, it has become problematic to find a measurable term to clarify the meaning of flexibility in business studies [10].

Much research related to flexibility and its relationship with performance has focused on financial performance e.g., [11-14]. However, other kinds of non-financial performance measurements should be considered, such as customer satisfaction [15-17], and this study tries to cover this gap by investigating the effect of strategic flexibility on customer satisfaction and in addition to operational and financial performance. Moreover, this study also focuses on strategic flexibility and its effects on the performance of SMEs, because of the claim that, compared with big companies, SMEs have a special skill, which is rapid adaption to environmental changes and fluctuations [18].

This study considered SME pharmaceutical companies in Iran for many reasons. According to the report by Roland Berger an international company located in Germany, there are many reasons motivating foreign investments to enter the Iranian market, especially the pharmaceutical market, which provides attractive growth opportunities. These reasons include the following: (1) Positive market dynamics: despite sanctions and turbulence in Iran, Iran's pharmaceutical sector is expected to expand at a compound annual growth rate of six percent to 2025, to become the fourth-ranked in the Middle East and North Africa. (2) An established pharmaceutical infrastructure: because of sanctions, Iran has established a substantial, self-sufficient medicine production infrastructure, and pharmaceutical companies manufacture approximately forty billion medicine units annually, an amount which meets ninety-six percent of local demand. (3) A skilled workforce: Iranian human capital is well-educated and qualified enough to run processes in different sectors, and the pharmaceutical sector is one of these. (4) Competitiveness: The Iranian pharmaceutical market is a dynamic one, the companies' active in the sector generated revenues of over USD 3.3 billion in 2018. (5) The geographical location: since the beginnings of history until the present day, from the former Silk Road to the current One Belt, One Road project, Iran as a country has had a competitive advantage because of its geographical location on international trade routes.

Based on what has been mentioned previously, this research tries to examine the impact of strategic flexibility on the performance of Iranian SME pharmaceutical companies and consider the moderating role of supply and demand uncertainty.

\section{State of Problem}

Generally, flexibility enables companies to achieve and maintain a competitive advantage. Moreover, in the field of product innovation for industrial companies, the importance of flexibility is growing, as a mechanism for building sustainable competitive advantage [19].

As an industrial country, Iran is a developing country located in the Middle East which has suffered and still suffers much political and economic turbulence. After the Islamic revolution in 1979 which was a turning point in Iran, the Iranian government paid great attention to the resources of the national healthcare system, especially in the pharmaceutical industry. However, Iran's pharmaceutical market is considered an unstable market that suffers from fluctuations over time [20], and these political and economic fluctuations could be a source of uncertainty.

Flexibility is a new topic for Iranian companies, especially in the light of the uncertainty in the business environment, and it could be useful for them to help them improve their performance.

For the current study, small and medium-sized pharmaceutical companies were considered as target companies, because SMEs make up more than $65 \%$ of the pharmaceutical sector in Iran. Moreover, generally, small and medium-sized enterprises (SMEs) face a critical problem, which is the inability to offer products/services on time and in the optimal 
way to meet customers' needs, and the inability to reduce the negative effect of demand fluctuations, and to improve and offer new products more quickly, all of which are considered important issues in the light of the intense competition in the market [21]. In this regard flexibility as a strategic technique can help SMEs to pass these problems.

Therefore, this research tries to answer the following questions:

(1) How does strategic flexibility affect companies' performance?

(2) How could uncertainty moderate the relationship between strategic flexibility and companies' performance?

Based on what has been mentioned previously, the research hypotheses can be summarized as:

Hypotheses 1 (H1). Strategic flexibility positively affects the performance of pharmaceutical SMEs in Iran.

Hypotheses 1a (H1a). Recourse flexibility positively affects the performance of pharmaceutical SMEs in Iran.

Hypotheses $\mathbf{1 b}(\mathbf{H 1} \mathbf{b})$. Coordination flexibility positively affects the performance of pharmaceutical SMEs in Iran.

Hypotheses 2 (H2). Uncertainty moderates the relationship between strategic flexibility and the performance of pharmaceutical SMEs in Iran.

\section{Literature Review}

\subsection{Strategic Flexibility}

Flexibility is a good mechanism to cope with uncertain situations and respond to fluctuations in the dynamic business environment and is considered a strategic merit and is an alternative approach to managing an uncertain future in the light of product competition [22]; moreover, it is used to develop companies' ability to react fast to the threats of technological change and to grab opportunities in the market $[23,24]$. Strategic flexibility is considered a reaction to uncertain situations and a customizing of available resources [19], which means "coordination flexibility" in order to enhance company performance, and this matches the aim of the current study. The literature related to competition [25] clarified that companies should adapt according to the competitive situation. So strategic flexibility could be a good mechanism to adapt to a competitive situation as well as market uncertainty. In the same direction, some studies have reported that strategic flexibility affects a company's performance, especially in a highly competitive environment [19].

\subsubsection{Resource Flexibility}

Resources refer to all the inputs including tangible and intangible assets (capital, assets, information, processes, etc.) which the organization uses to implement the strategies and achieve the required aims [26]. Because of the scarcity of resources, and the multi-use of them, companies can obtain many benefits and advantages by developing strategic flexibility in order to share and use their rare resources in a flexible manner [27]. In this regard, resource flexibility as a type of strategic flexibility has an advantage as an enabler or antecedent for the flexibility of the operational system, which will lead to a boost in operational performance and, as a result, a competitive advantage [28]. From a strategic perspective, resource flexibility is described using three dimensions: (a) a range of alternatives, (b) cost, and (c) time. Studies clarified that resource flexibility relates positively to a variety of alternative uses of the available resources [29]. There are inverse relationships between both cost (the costs and difficulty of changing between alternatives) and time (which is needed for switching between the alternatives) and resource flexibility. The importance of RF is shown by the ability to use available resources to efficiently conduct a wide range of operational activities, especially in reacting. 


\subsubsection{Coordination Flexibility}

In the context of coordination flexibility as a type of strategic flexibility, we should search for details in coordination, beginning with understanding that coordination is the creative side of an organization [30]. Moreover, coordination itself includes three main processes: (a) defining both production and marketing strategies to determine the market segments it aims to reach by offering the products; (b) determining the resources needed to produce and distribute the products in the light of both production and marketing strategies, and (c) re-customizing resources by forming effective and suitable marketing channels which support the production strategies in the target markets [30]. Coordination flexibility could be used by companies to react to the changes in a dynamic environment and exploit the available opportunities [31] and serve potential customers [32], and as a result enhance company performance. Moreover, it enables the company to reconfigure and redesign the usual administrative processes and apply them with a new method, in order to save the time needed and minimize the accompanying costs of production processes, and so enhance and improve the production strategies applied [33].

\subsection{Environmental Uncertainty}

Globalization has weighed heavily on the business environment, making it complex, risky and uncertain, and this has become a fact of the turbulent business environment, and the reason which has pushed organizations to look for mechanisms to adapt to emergency situations and changes in their work environment. Consequently, uncertainty is an important topic for many researchers and has been the focus of many research papers that have investigated the link between the organization and its environment, especially considering ideas rooted in organizational theory. In the context of organization definition, the organization can be referred to as a system (inputs, process, and outputs) linked with the environment in which it operates, which means it affects and is affected by the environment [34].

\subsubsection{Demand Uncertainty}

The business environment has changed a great deal. In the past, demand was steadier, because the product life cycle was longer and product variety was less [35]. Nowadays, the opposite case predominates in the market; demand uncertainty caused by demand fluctuations is considered one of the most important types of uncertainty which companies face. Due to demand uncertainty, companies should observe changes in customers preferences and modify their products to match the new consumption trends [25]. So companies should be flexible enough to make the required adjustments in the perfect time. In this regard, the literature reports that companies will earn less profit because of demand fluctuations; in this case, the advantages of flexibility implementation will be valuable [23].

\subsubsection{Supply Uncertainty}

As a system, any company is basically structured on input, process and output; therefore, a company's ability to provide reliable outputs and fulfil customer needs depends on obtaining the inputs at the perfect time and in the required quality. Consequently, companies should consider the supply-side and the uncertainty related to it. Supply uncertainty has become a fact and a problem facing all companies which obtain the required inputs for the processes by outsourcing, regardless of the nature of the activities or the field that the company operates in [36]. Other researchers have emphasized that supply uncertainty has become a major challenge in the field of SCM [37]. In general, there are many reasons for supply uncertainty, such as the average lateness, manufacturing downtime, order-entry errors, the degree of inconsistency and on-time performance, quality standards, logistics errors, inaccurate forecasting [24,38], timeliness and the selection criteria of the suppliers [39]. 


\subsection{Companies' Performance}

Companies' performance is the old issue of modern times, and is still attractive for the researcher in the field of business and management, perhaps because there is no standard measurement of a company's performance, so it can be measured with different methods. Performance is considered a measurement which expresses the extent to which the company is able to run its activities and process efficiently and effectively, and then to judge if it is successful or not, and if it can survive in the market or has to leave [35]. In general, we can find two major classifications of a company's performance measurements, i.e., financial measurements and non-financial measurements. From a financial perspective, financial performance is one of the most important measurements of performance [39,40]. Non-financial measures can encompass different ways of measuring the objectives in the long term, such as operational performance, efficiency, customer satisfaction, and effectiveness, which are used to measure internal operations [41]. Moreover, many non-financial measures have been widely used to evaluate companies' performance, such as market share, quality, and customer satisfaction [42]. It has also been mentioned that administrative procedures in the short-term which relate, for example, to operational activities, quality, and innovation, will enhance and reflect positively on financial performance in the future $[43,44]$. In the current study, we will focus on the subjective measurement of financial performance, and non-financial performance measurements, such as operational performance, and customer satisfaction.

\section{Research Methodology}

This study is a quantitative one. The study's aim is to search for the link between flexibility and the performance of small and medium-sized pharmaceutical companies in Iran, in the light of uncertainty and to test the theoretical background to establish to what the extent strategic flexibility affects companies' performance, and if uncertainty moderates this relationship.

The data used in this research is primary; a questionnaire adapted from the literature has been used to collect primary data, with the questionnaire being forwarded to all SME pharmaceutical companies in Iran. Regarding the statistical analysis, the following techniques were used: descriptive analysis, linear regression analysis, and moderation analysis [44].

Time Horizon: This study is a cross-sectional one, which means the study was carried out at a specific time (2019) and does not cover a time series.

Population and sample: Pharmaceutical companies in Iran can be categorized into small, medium and large, based on the maximum annual income or turnover. This study considers only small and medium-sized pharmaceutical companies.

Sampling: a purposive (selective) sampling technique was used to collect the data, targeting three managers from each company: the production manager, the marketing manager, and the sales manager from each company were asked to fill in the questionnaires, because these managers have enough experience, information, and knowledge to respond to the questions rationally and accurately.

Data and Data Collection Process: for the current research, the data was collected using an adopted questionnaire, which is primary. The questionnaire was forwarded to the target sample at the SME pharmaceutical companies in large cities in Iran (Tehran, Mashhad, Qazvin, Isfahan, and Shiraz). The respondents answered the questions without mentioning their names, following confidentiality standards at the target companies. The questionnaire was designed to be only five pages in length to make the respondents feel comfortable and to answer it easily within $30 \mathrm{~min}$.

Most of the managers gave serious attention to answering the questions and provided some advice relating to their business, according to their particular vision. On the other hand, some of them were not serious and chose to answer most of the questions in a neutral fashion. Some of them did not answer many of the questions in the questionnaire and so we could not consider them because of the high number of this kind of missing value 
in each questionnaire. The uncompleted questionnaires were not used at all because this would have damaged the results of the study.

The total number of responses that were valid for statistical analysis was 228; the intention was to receive 339 responses from 113 companies (three questionnaires for each company). The response rate was $67.25 \%$.

\section{Results}

\subsection{Test of Reliability}

The first step is to check the reliability of the measures used and the extent to which it is consistent, by using the Cronbach Alpha test to measure the reliability of the variables used in the questionnaire and the degree of homogeneity in the measurement.

Loading values can be accepted lower than $60 \%$ (>0.60). Of 29 items in Table 1 , the minimum value was higher than $50 \%$ [20]. The results show the statistical significance of the relationships between the items and constructs and the reliability of individual items. The results of Cronbach's Alpha test for each variable are summarized in Table 1.

Table 1. The Results of Reliability Test.

\begin{tabular}{|c|c|c|c|}
\hline No & Scale & $\begin{array}{l}\text { Cronbach's } \\
\text { Alpha }\end{array}$ & Loadings \\
\hline 1. & Uncertainty & 0.719 & \\
\hline UN1 & The suppliers always seek to fulfil your needs & & 0.640 \\
\hline UN2 & The suppliers provide you with good quality materials consistently. & & 0.797 \\
\hline UN3 & The demand is unpredictable. & & 0.796 \\
\hline UN4 & The demand fluctuates every week. & & 0.622 \\
\hline UN5 & Both demand and consumer preferences are almost unpredictable. & & 0.731 \\
\hline 2. & Resource Flexibility-RF & 0.745 & \\
\hline R1 & We can use our resources in different ways & & 0.556 \\
\hline $\mathrm{R} 2$ & We can change the use of major resources to a different usage easily. & & 0.781 \\
\hline $\mathrm{R} 3$ & We can switch to alternative resource use is short time. & & 0.717 \\
\hline $\mathrm{R} 4$ & We can use our resources to develop, produce, and deliver a variety of products. & & 0.511 \\
\hline R5 & We have the ability to get new resources as alternative resources to the available resources. & & 0.571 \\
\hline 3. & Coordination Flexibility-CF & 0.704 & \\
\hline $\mathrm{C} 1$ & We have the ability to determine the required resources for production processes. & & 0.563 \\
\hline $\mathrm{C} 2$ & $\begin{array}{c}\text { We have the ability to form and determine the optimal structure of resources which match with } \\
\text { production plan. }\end{array}$ & & 0.630 \\
\hline C3 & Our internal units work together to find the optimal use of available resources. & & 0.770 \\
\hline C4 & We have the ability to manage and use our resources in an efficient way to match the production plan. & & 0.828 \\
\hline C5 & We have the ability to redefine the new use of available resources to reconfigure the resource chain. & & 0.556 \\
\hline 4. & Financial Performance-FP & 0.924 & \\
\hline FP1 & My company is profitable. & & 0.934 \\
\hline FP2 & My company sales are growing. & & 0.959 \\
\hline FP3 & My company market share is growing. & & 0.907 \\
\hline 5. & Customer satisfaction-CS & 0.754 & \\
\hline CS1 & Our customers are loyal to our products. & & 0.604 \\
\hline CS2 & Our customers are satisfied with the price and quality of the products that we offer to them. & & 0.811 \\
\hline CS3 & Customers are comfortable and satisfied in spending money to buy our products. & & 0.820 \\
\hline CS4 & Our company has a good reputation for our products. & & 0.598 \\
\hline CS5 & We able to satisfy our customers much better than our main competitors. & & 0.753 \\
\hline 6. & Operational performance-OP & 0.770 & \\
\hline OP1 & We can quickly modify products to fulfil customers' needs. & & 0.734 \\
\hline OP2 & We can quickly respond to demand fluctuations. & & 0.730 \\
\hline OP3 & Our customers are satisfied with timely delivery. & & 0.704 \\
\hline OP4 & The waiting time (from the order until delivery) is short. & & 0.727 \\
\hline OP5 & At our company, customer service quality is high. & & 0.663 \\
\hline OP6 & Our operational performance is better than the performance of main competitors in the industry. & & 0.739 \\
\hline
\end{tabular}

Source: Based on the authors' calculations.

We can note that the value of the Cronbach's Alpha values of the current study is located in the range 0.704-0.924, which means the scale or the questionnaire used to measure the variables is a reliable and steady one, because according to [44],the value of the alpha is bound between 0 and 1 and it can be used with questionnaires which have a 
scale from 0 as the worst value, to 5 as the best, and if the alpha value is 0.70 this can be acceptable; indeed, lower values have also been accepted in some of the literature.

\subsection{Descriptive Analysis}

For the descriptive analysis, the mean and standard deviation was calculated. Table 2 presents the summary of the results of the descriptive analysis.

Table 2. Descriptive analysis.

\begin{tabular}{cccc}
\hline Variables & Mean & Std. Deviation & $\mathbf{N}$ \\
\hline SU & 3.825 & 0.5005 & 228 \\
DU & 3.84 & 0.516 & 228 \\
RF & 4.044 & 0.457 & 228 \\
CF & 3.992 & 0.559 & 228 \\
FP & 4.10 & 0.617 & 228 \\
OP & 3.78 & 0.562 & 228 \\
CS & 3.86 & 0.624 & 228 \\
\hline
\end{tabular}

Source: Authors' calculations.

The supply uncertainty results $(M=3.825, \mathrm{SD}=0.5005)$ mean that there is an agreement among the respondents that the target companies face SU. M equals $3.82 \approx 4$ matches the value for "agree" on the scale used. Std Deviation refers to the extent to which the values are far from or close to the mean.

Accordingly, the value for SU will be $3.825 \pm 0.5005=\{3.32,4.325\}$. In other words, all the responses are between 'neutral' and 'agree' based on the scale used. Moreover, the minimum value of $S U$ equals 2 and the maximum equals 5, which means all the responses ranged between 2 and 5 according to the scale used.

Demand uncertainty: $(M=3.84, S D=0.516)$, which means that all the responses are between 'neutral' and 'agree' based on the scale used.

Resource flexibility: $(\mathrm{M}=4.044, \mathrm{SD}=0.457)$, which means $\mathrm{RF}$ is applied at the target companies.

Coordination flexibility: $(\mathrm{M}=3.992, \mathrm{SD}=0.559)$, which means there is an agreement among the respondents that the target companies apply CF as a mechanism to deal with uncertainty. Financial performance: $(\mathrm{M}=4.10, \mathrm{SD}=0.617)$, which means there is an agreement among the respondents that the financial performance of the target companies is rated as good.

Operational performance: $(\mathrm{M}=3.78, \mathrm{SD}=0.562)$, which means there is an agreement among the respondents that the operational performance of the target companies is rated as good.

Customer satisfaction: $(\mathrm{M}=3.86, \mathrm{SD}=0.624)$, which means there is an agreement among the respondents that $\mathrm{CS}$ is rated as good. $\mathrm{M}=3.86 \approx 4$ matches the value for 'agree' on the scale used.

\subsection{Correlation Analysis}

The correlation test was carried out with the Pearson correlation test, in order to understand the degree of correlation between the variables. Table 3 explains that the correlation between the variables is either moderate or low, but all the correlation relations were significant. The correlations between the independent variables (RF, CF) and dependent variables (FP, OP, and CS) were significantly correlated. 
Table 3. Correlations Results.

\begin{tabular}{ccccc}
\hline & UN & RF & CR & Performance \\
\hline UN & 1 & & & \\
RF & $0.358^{* *}$ & 1 & & \\
CR & $0.270^{* *}$ & $0.469^{* *}$ & 1 & 1 \\
Performance & $0.538^{* *}$ & $0.537^{* *}$ & $0.449^{* *}$ & 1 \\
\hline
\end{tabular}

Source: Authors' calculations. ${ }^{* *}$ Correlation 0.01 level.

In more detail, the results showed that uncertainty is significantly positively related with RF, CF. This provides evidence that uncertainty affects managers' decisions to adopt flexibility as a mechanism to deal with unexpected situations. Uncertainty was also positively related with companies' performance; from this point of view, the performance of the target companies is still good despite uncertainty, due to the implementation of flexibility as a mechanism to deal with uncertain situations. This implies clearly the importance of flexibility as a mechanism to enhance companies' performance despite uncertainty. In this case, uncertainty could not affect companies' performance negatively.

$\mathrm{RF}, \mathrm{CF}$ are linked to company performance significantly and positively; this obviously indicates the significance of $\mathrm{SF}$ as an effective technique to enhance companies' performance. Along with this, it clarifies the possibility of controlling the negative effect of uncertainty by using perfect techniques such as flexibility.

\subsection{Regression Analysis}

In order to test the first main hypothesis and the sub-hypotheses related to it, linear regression analysis (Enter) was used to investigate the causal relationship between strategic flexibility and companies' performance.

According to the results in Table 4, strategic flexibility affects company performance positively, and strategic flexibility explains $33.2 \%$ of performance variance. Depending on the summarized results in Table 4, we can agree with the first main hypothesis, i.e., that "strategic flexibility positively affects the performance of SME pharmaceutical companies in Iran".

Table 4. Regression results of different dimensions of flexibility-Total performance.

\begin{tabular}{cc}
\hline & Dependent Variable \\
\hline Independent Variables & Performance \\
Constant & Model 1 \\
RF & $0.784^{* * *}$ \\
CF & $0.534^{* * *}(0.418)$ \\
R & $0.244^{* * *}(0.253)$ \\
Adjusted $R^{2}$ & 0.582 \\
\hline
\end{tabular}

Source: Authors' calculations. Levels of significance: ${ }^{* * *} p<0.001$.

Table 4 shows that resource flexibility affects company performance positively and has a greater effect on company performance $(41.8 \%)$ which refers to the Standardized Beta Coefficient that compares the strength of the effect of each individual independent variable to the dependent variable. The higher the absolute value of the beta coefficient, the stronger the effect. So the sub-hypothesis 1a that "resource flexibility positively affects the performance of SME pharmaceutical companies in Iran" is accepted.

Moreover, coordination flexibility affects company performance positively, and its effect on it is equivalent to $25.3 \%$ (Standardized Beta Coefficient), so the sub- hypothesis $1 \mathrm{~b}$ that "coordination flexibility positively affects the performance of SME pharmaceutical companies in Iran" is accepted.

Based on the coefficient results, we can form a regression equation, as follows:

$$
Y=0.784+0.534 X 1+0.244 X 2
$$


where $\mathrm{X} 1$ : RF, $\mathrm{X} 2$ : CF, $\mathrm{Y}=$ companies Performance.

Based on the above, Figure 1 summarizes the effect of dimensions of strategic flexibility on the performance of SME pharmaceutical companies in Iran.

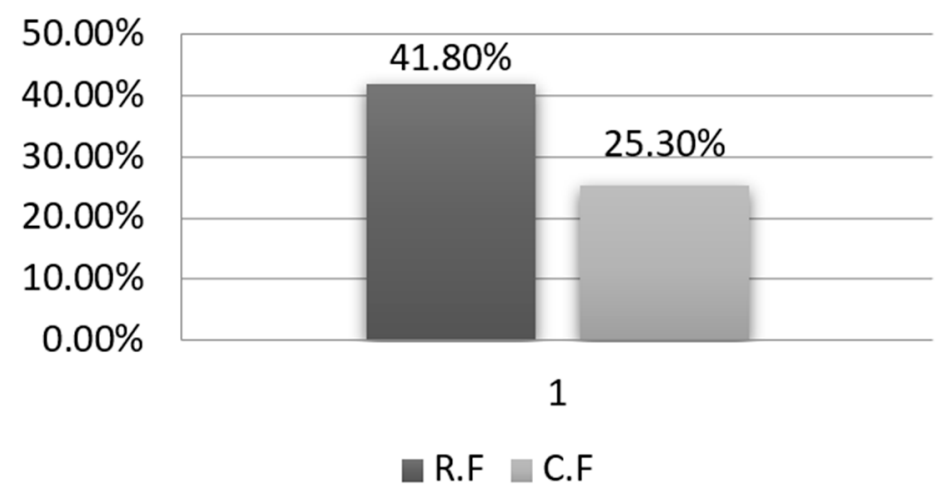

Figure 1. The Effect of Flexibility Dimensions on Companies' Performance. Source: Authors' calculation (2019).

Resource flexibility affects the performance of SME pharmaceutical companies in Iran positively, and it has the highest impact on performance- $41.8 \%$.

Coordination flexibility affects the performance of SME pharmaceutical companies in Iran positively, and it has the lowest impact on performance-25.3\%.

For more details about the relationship between different dimensions of strategic flexibility and different dimensions of performance, Table 5 shows the details of the causal relationship between the variables.

Table 5. Regression Analysis of Different Dimensions of Flexibility-Different Dimensions of Performance.

\begin{tabular}{|c|c|c|c|}
\hline & \multicolumn{3}{|c|}{ Dependent Variable } \\
\hline & \multicolumn{3}{|c|}{ Performance } \\
\hline \multirow[t]{2}{*}{$\begin{array}{l}\text { Independent } \\
\text { Variables }\end{array}$} & & Model 1 & \\
\hline & FP & CS & OP \\
\hline Constant & $1.171^{* *}$ & 0.450 & 0.730 * \\
\hline $\mathrm{RF}$ & $0.764^{* * *}(0.382)$ & $0.534 * * *(0.339)$ & $0.303^{* * *}(0.231)$ \\
\hline $\mathrm{CF}$ & $-0.039(0.026)$ & $0.313^{* * *}(0.263)$ & $0.459 * * *(0.463)$ \\
\hline $\mathrm{R}$ & 0.370 & 0.518 & 0.607 \\
\hline Adjusted $\mathrm{R}^{2}$ & 0.129 & 0.262 & 0.362 \\
\hline
\end{tabular}

Based on Table 5, we can provide more details about the direct effects of SF dimensions on the dimensions of performance. Based on the values of the Standardized Beta Coefficient, resource flexibility positively affects performance dimensions as follows:

Financial performance- $38.2 \%$, customer satisfaction-33.9\%, operational performance $-23.1 \%$.

Coordination flexibility does not affect financial performance, whereas it affects customer satisfaction and operational performance positively. Based on the values of the Standardized Beta Coefficient, coordination flexibility positively affects only two of performance dimensions as follows: customer satisfaction-26.3\%, operational performance- $46.3 \%$.

In Table 6, based on the values of the Standardized Beta Coefficient, strategic flexibility in general positively affects performance dimensions as follows: financial performance $(28.6 \%)$, customer satisfaction $(51.1 \%)$, and operational performance $(60.3 \%)$. 
Table 6. Regression Analysis of Different Dimensions of Flexibility—Different Dimensions of Performance.

\begin{tabular}{|c|c|c|c|}
\hline & \multicolumn{3}{|c|}{ Dependent Variable } \\
\hline & \multicolumn{3}{|c|}{ Performance } \\
\hline \multirow{2}{*}{$\begin{array}{l}\text { Independent } \\
\text { Variables }\end{array}$} & & Model 1 & \\
\hline & FP & CS & OP \\
\hline Constant & $1.797 * *$ & $0.623^{* * *}$ & $0.608^{* * *}$ \\
\hline SF & $0.573^{* * *}(0.286)$ & $0.805^{* * *}(0.511)$ & $0.791^{* * *}(0.603)$ \\
\hline $\mathrm{R}$ & 0.286 & 0.511 & 0.603 \\
\hline Adjusted $\mathrm{R}^{2}$ & 0.078 & 0.258 & 0.360 \\
\hline
\end{tabular}

Source: Based on the authors' calculations. Levels of significance: ${ }^{* *} p<0.01 ;{ }^{* * *} p<0.001$.

\subsection{Moderation Analysis}

In order to test the second main hypothesis related to the moderation effect, Moderation Analysis was conducted using SPSS 25 (company, city, state abbrev if USA, country), by using the PROCESS introduced by Andrew Hayes. For this purpose, the new edition was presented in 2018. Add-on macros were installed in the SPSS program, as this was helpful to analyse the interaction effects.

First, a regression model is fitted predicting the dependent variable (performance) from the independent variable (strategic flexibility) and the moderator variable (uncertainty). Then, the interaction effect is added to the previous model (block 2) and a check is carried out for a significant R2 change, as well as a significant effect by the new interaction term. If both are significant, then moderation is occurring.

Based on Table 7, SF is positively related to company performance. Based on the values of the Standardized Beta Coefficient, strategic flexibility in general positively affects companies' performance- $56.6 \%$. The relationship is significant, and strategic flexibility explains $31.8 \%$ of the variance of companies' performance (based on R adjusted square value), where $\mathrm{R}^{2}$ or "R squared" refers to the coefficient of determination, which is the proportion of the variation in the dependent variable that is predictable from the independent variable.

Table 7. Regression Analysis of Flexibility-Performance.

\begin{tabular}{cc}
\hline & Dependent Variable \\
\hline Independent Variables & Performance \\
Constant & Model 1 \\
SF & $1.009^{* * *}$ \\
$\mathrm{R}$ & $0.723^{* * *}(0.566)$ \\
$\mathrm{R}^{2}$ & 0.566 \\
\hline
\end{tabular}

Source: Author's calculations. Statistical significance: ${ }^{* * *} p<0.001$.

In order to do moderation analysis, we should do heteroscedasticity, and a normality of residuals test. The test was done using SPSS 23, and the results showed that the data follows the normal distribution and there is no heteroscedasticity in regression analysis and the analysis of variance (the figures are available in Appendix B).

The Moderating Effect of Uncertainty on the Relationship between Strategic Flexibility and Performance

Table 8 shows the result of the moderating effect of uncertainty on the link between SF and the performance of SME Pharmaceutical companies in Iran. 
Table 8. The Results of Moderated Regression Analysis (Uncertainty as Criterion).

\begin{tabular}{|c|c|c|c|c|c|}
\hline & B & $\mathbf{R}$ & $\mathbf{R}^{2}$ & $\mathrm{~T}$ & $p$ \\
\hline Constant & $\begin{array}{c}8.54^{* * *} \\
{[3.56,13.51]}\end{array}$ & & & 3.381 & 0.0009 \\
\hline SF & $\begin{array}{c}-1.6775 * * * \\
{[-2.96,-0.38]}\end{array}$ & 0.6906 & 0.4769 & -2.561 & 0.0111 \\
\hline Uncertainty & $\begin{array}{c}-1.97^{* * *} \\
{[-3.37,-0.566]}\end{array}$ & & & -2.76 & 0.0062 \\
\hline$S F * U n$ & $\begin{array}{c}0.62 * * * \\
{[0.265,0.98]}\end{array}$ & & $0.0272^{* * *}$ & 3.41 & 0.0008 \\
\hline
\end{tabular}

Based on Tables 7 and 8, regarding the relationship between strategic flexibility and companies' performance, uncertainty was a significant moderator for the relationship: $R=0.6906, \mathrm{R} 2=0.4769, p=0.0111, R 2$-chng $=0.0272, p=0.0008$.

In this case the moderation effect of uncertainty on the relationship between strategic flexibility and companies' performance is significant but based on R2 and R2-chng values; we noted that the direct relationship between strategic flexibility and companies' performance was stronger before using uncertainty as a moderator.

According to the previous Table 8 , we can note that all $p$ values are significant: $p<0.001, p<0.05$, and according to the following ranges [3.56, 13.51], [-2.96, -0.38$]$, $[0.265,0.98]$, there is no (0) value between the lower and the upper value for each one of them where the previous ranges refer to the values of LLCI-ULCI as outcomes of moderation analysis. Consequently, we can say that uncertainty moderates the relationship between SF and company performance, because $p<0.001, p<0.05$, and the two values of each range are either positive or negative (both of them are negative or both of them are positive in the same range), on the basis of which we accept the third main hypothesis that "uncertainty moderates the relationship between SF and company performance".

The interaction term was statistically significant $(b=0.6269$, s.e. $=0.1836, p=0.0008)$ in our model, indicating that uncertainty significantly moderates the effect of flexibility on company performance.

Since the interaction term in the model was statistically significant, we have to probe the interaction in order to better interpret the nature of the moderated relationship between strategic flexibility and company performance, at three levels of the moderator.

At level 1 (i.e., 3.5834) on the lowest level of uncertainty, the relationship between strategic flexibility and company performance was positive and significant: $b=0.5690$, se $=0.0664, \mathrm{t}=8.56, p=0.0000<0.001$.

At level 2 (i.e., 3.8750) on the average level of uncertainty, the relationship between strategic flexibility and company performance was positive and significant: $b=0.7518$, Se $=0.0892, \mathrm{t}=8.4277, p=0.0000<0.001$.

At level 3 (i.e., 4.0000) on the highest level of uncertainty, the relationship between strategic flexibility and company performance was positive and significant: $b=0.8302$, $\mathrm{Se}=0.1060, \mathrm{t}=7.8323, p=0.0000<0.001$.

This result of Table 8 shows that in uncertain situations if the pharmaceutical companies use strategic flexibility as a mechanism to deal with uncertainty it will reflect positively on their performance. So in uncertain business environments when companies carry out strategic flexibility, the performance of these companies will be improved due to the fact that flexibility is an effective technique to adapt to an uncertain environment.

Figure 2 shows the moderating effect of uncertainty on the relationship between strategic flexibility and performance, at different levels of uncertainty. 


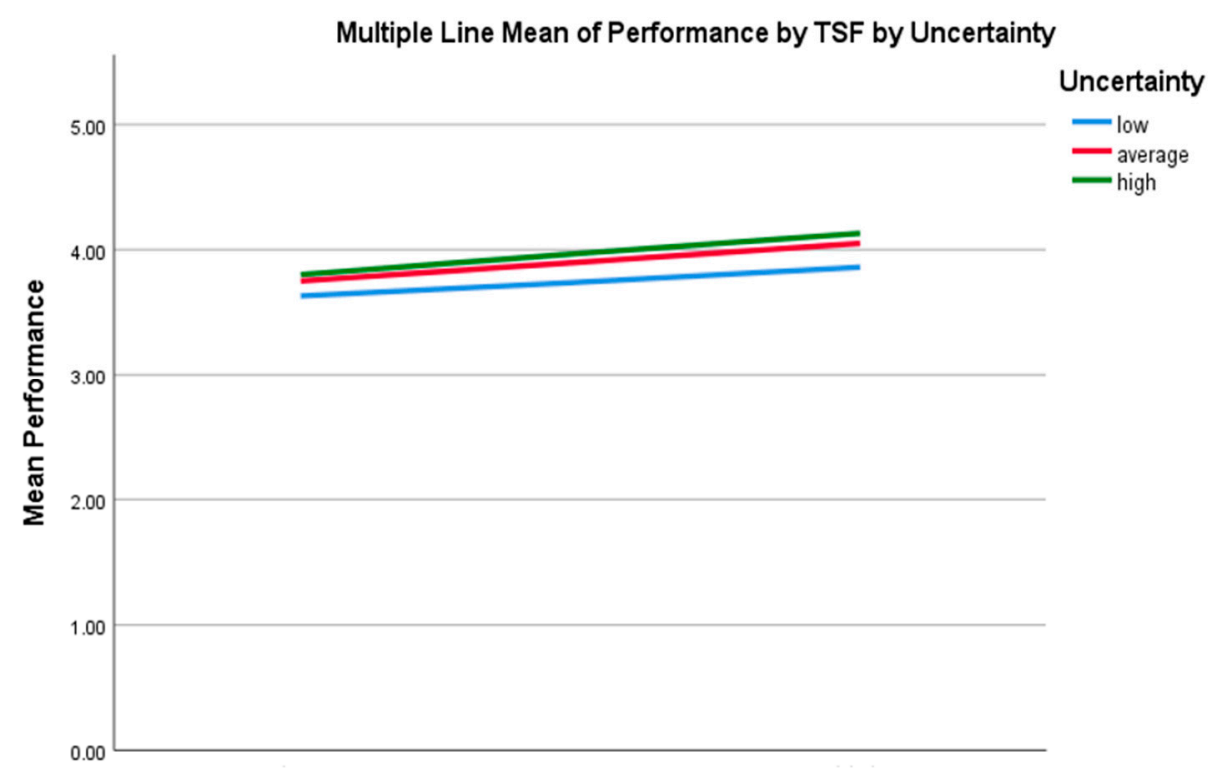

Figure 2. The Moderating effect of uncertainty on the relationship between strategic flexibility and companies' performance. Source: Authors' calculations.

According to Figure 2, we can note that there is a positive relationship between strategic flexibility and companies' performance in the light of uncertainty. The values of performance ranged between 3 and 4, whereas the values of TSF (total strategic flexibility) are ranked as low, average and high. We can note there are three lines with different colours, the blue one shows the positive relationship between SF and companies' performance moderated by a low level of uncertainty. The same goes for the red colour which refers to the positive relationship between SF and companies' performance moderated by the average level of uncertainty. Finally, the green colour shows the positive relationship between SF and companies' performance moderated by a high level of uncertainty. The direction of the slopes shows the positive relationship between strategic flexibility and companies' performance in the light of uncertainty. In the three different cases shown by the three different colours, we can note that with each increase of the SF level the performance of the companies' increases in the light of different levels of uncertainty.

SF affects the performance of SME pharmaceutical companies in Iran positively. According to the results, both resource flexibility and coordination flexibility positively affect the performance of the target companies, and it seems clear that carrying out strategic flexibility can be considered an effective mechanism to deal with uncertainty and to enhance the performance of SME pharmaceutical companies in Iran. For more details about the effect of strategic flexibility dimensions on performance dimensions, the results showed that resource flexibility positively affects the financial performance, customer satisfaction, and operational performance of the target companies. Also, coordination flexibility positively affects customers.

If we turn to the moderation effect of uncertainty on the relationship between strategic flexibility and company performance, we can observe that, based on moderation analysis, uncertainty moderates the link between strategic flexibility and company performance, which means that in uncertain situations, the effects of strategic flexibility on company performance will be greater, and this indicates the importance of strategic flexibility as a mechanism to deal with environmental uncertainty.

\section{Discussion and Conclusions}

In a hyper-changeable business environment, businesses should try to manage all these changes and respond to them by being agile and trying to control unexpected situations as much as they can. As a result, a company will be able to deal with uncertain situations, 
avoid threats and grab opportunities. Flexibility relies on two fundamental elements: first, the speed of reaction, and second, the availability of information in uncertain situations.

In general, the results indicate that Iranian SME pharmaceutical companies work in an uncertain business environment, and they use strategic flexibility as mechanism to deal with uncertain situations. The performance of these companies is rated as good. Strategic flexibility positively affects the performance of SME pharmaceutical companies in Iran.

Strategic flexibility, represented by resource flexibility and coordination flexibility, affects positively and significantly the performance of SME pharmaceutical companies in Iran, and this result matches the results of [18], i.e., that resource flexibility is a way to meet customers' demands faster, will lead to customer satisfaction, and will enhance the financial performance of the company $[19,23]$. It also matches the results of [16] who found that an effective allocation and utilization of resource flexibility helps companies to improve performance.

Environmental uncertainty moderates the link between strategic flexibility and the performance of target companies. Strategic flexibility works as an umbrella for operational flexibility, which means that when strategic flexibility represented by resource flexibility and coordination flexibility exists, it will reflect positively on performance and is a realistic mechanism to cope with external environmental uncertainty which is represented by supply uncertainty and demand uncertainty. When resource flexibility is high and affects company performance positively, these companies will have good techniques to deal with different suppliers and obtain the resources required for production processes. Despite the importance of resource flexibility in enhancing companies' performance, there is no benefit if the company cannot manage the available resources in an economical way to reach the optimal level of resource usage, because resources are limited and they should be used rationally. Consequently, coordination flexibility will be a perfect mechanism to achieve this, especially when the outcomes clarify that coordination flexibility positively affects the performance of SME pharmaceutical companies in Iran. It is hoped that the findings of this paper will help scholars and policymakers in the field of business performance.

\section{Research Limitations}

Like other research, this study has many limitations. First of all, the study considered one manufacturing sector, i.e., pharmaceutical companies, and moreover, it only dealt with SMEs, so for future studies, researchers could consider large companies as well, and make a comparative study between different industrial sectors to investigate the impact of flexibility on performance, because this relationship still needs much investigation.

Second, the current study used two dimensions of strategic flexibility. Other researchers can use different dimensions from a different perspective, and environmental uncertainty and performance can be considered from different perspectives by using different dimensions of both of them. Moreover, different factors can be considered as moderators or mediators for this relationship.

Third, this study considered Iran as a country; future studies can make comparative studies between different countries because different countries mean different business environments, different sources of uncertainty, and logically different results.

Fourth, this study is a cross-sectional one, so perhaps a larger research project could use long term series to make comparisons based on time differences.

Finally, it would be beneficial to consider the synergistic effect of another practice, such as market orientation with flexibility to enhance company performance.

Author Contributions: Conceptualization, J.F.; methodology, A.Y.; software, J.O.; validation, A.Y., V.Z.L.; formal analysis, A.Y., J.F., J.O.; investigation, A.Y.; resources, A.Y.; data curation, A.Y.; writingoriginal draft preparation, A.Y.; writing—review and editing, J.O.; visualization, J.F.; supervision, J.F.; project administration, J.F.; funding acquisition, J.O.; data analysis, A.Y.; data collection, V.Z.L. All authors have read and agreed to the published version of the manuscript. 
Funding: This paper is supported by EFOP-3.6.3-VEKOP-16-2017-00007__"Young researchers for talent" - supporting careers in research activities in higher education program.

Institutional Review Board Statement: Not applicable.

Informed Consent Statement: Not applicable.

Data Availability Statement: Not applicable.

Conflicts of Interest: The authors declare no conflict of interest. The founding sponsors had no role in the design of the study; in the collection, analyses, or interpretation of data; in the writing of the manuscript, and in the decision to publish the results.

\section{Abbreviations}

In this study some abbreviations have been used, including SF (strategic flexibility), RF (resource flexibility), CF (coordination flexibility), SU (supply uncertainty), DU (demand uncertainty), UN (uncertainty), FP (financial performance), CS (customer satisfaction), and OP (operational performance).

\section{Appendix A. Survey on the Effects of Flexibility on Performance of Companies in Business \\ Company Name ................ Main activity of the company ........ ........... \\ Company size

\begin{tabular}{l|c|c} 
Small & Medium & Large \\
\hline
\end{tabular}

The purpose of this survey is to analyze the degree of the effects of flexibility on performance in the light of uncertainty. This information will be strictly confidential and these data will always be aggregated in the eventual case of publication.

(1) Please indicate the degree of importance allocated in your company to each of the following flexibility dimensions, in comparison to other companies in your specific sector of competition. Use the five-point Likert scale (1 Strongly Disagree "SD") (2 Disagree “D”) (3 Neutral "N") (4 Agree "A") (5 Strongly Agree "SA").

\begin{tabular}{|c|c|c|c|c|c|c|}
\hline \multirow{2}{*}{$\begin{array}{l}Q \\
1\end{array}$} & \multirow{2}{*}{$\begin{array}{l}\text { Strategic Flexibility (Resource Flexibility) } \\
\text { We can use our resources in different ways }\end{array}$} & \multicolumn{5}{|c|}{ Scale } \\
\hline & & SD & $\mathbf{D}$ & $\mathbf{N}$ & A & SA \\
\hline 2 & $\begin{array}{c}\text { We can change the use of major resources to a different } \\
\text { usage easily. }\end{array}$ & & & & & \\
\hline 3 & We can switch to alternative resource use in a short time. & & & & & \\
\hline 4 & $\begin{array}{c}\text { We can use our resources to develop, produce, and deliver a } \\
\text { variety of products. }\end{array}$ & & & & & \\
\hline 5 & $\begin{array}{l}\text { We have the ability to get new resources as alternative } \\
\text { resources to the available resources. }\end{array}$ & & & & & \\
\hline $\mathbf{Q}$ & Strategic Flexibility (Coordination Flexibility) & & & Scale & & \\
\hline 1 & $\begin{array}{l}\text { We have the ability to determine the resources required for } \\
\text { production process. }\end{array}$ & SD & $\mathbf{D}$ & $\mathbf{N}$ & A & SA \\
\hline 2 & $\begin{array}{l}\text { We have the ability to form and determine the optimal } \\
\text { structure of resources which match the production plan. }\end{array}$ & & & & & \\
\hline 3 & $\begin{array}{l}\text { Our internal units work together to find the optimal use of } \\
\text { available resources. }\end{array}$ & & & & & \\
\hline 4 & $\begin{array}{l}\text { We have the ability to manage and use our resources in an } \\
\text { efficient way to match the production plan. }\end{array}$ & & & & & \\
\hline 5 & $\begin{array}{c}\text { We have the ability to redefine the new use of available } \\
\text { resources to reconfigure the resource chain. }\end{array}$ & & & & & \\
\hline
\end{tabular}

(2) Please indicate the degree of importance allocated in your company to each of the following uncertainty dimensions. Use the five-point Likert scale (1 Strongly Disagree "SD") (2 Disagree “D”) (3 Neutral “N") (4 Agree " $\mathrm{A}^{\prime}$ ) (5 Strongly Agree "SA"). 


\section{Demand Uncertainty}

SD

D $\quad$ N $\quad$ A

SA

1 The suppliers always seek to fulfil your needs

2 The suppliers provide you with good quality materials consistently.

3 The demand is unpredictable.

The demand fluctuates every week.

1 Both demand and consumer preferences are almost unpredictable.

(3) Please indicate the comparative performance of your company in relation to other competitive companies in your industry. Use the five-point Likert scale (1 Strongly Disagree "SD") (2 Disagree “D”) (3 Neutral "N") (4 Agree "A") (5 Strongly Agree "SA").

\begin{tabular}{|c|c|c|c|c|c|c|}
\hline Q & Business Performance (Financial) & SD & D & $\mathbf{N}$ & $\mathbf{A}$ & SA \\
\hline 1 & My company is profitable. & & & & & \\
\hline 2 & My company's sales are growing. & & & & & \\
\hline \multirow[t]{2}{*}{3} & My company's market share is growing. & & & & & \\
\hline & Business Performance (Customer Satisfaction) & SD & $\mathbf{D}$ & $\mathbf{N}$ & A & SA \\
\hline
\end{tabular}

1 Our customers are loyal to our products.

2 Our customers are satisfied with the price and quality of the products that we offer to them.

3 Customers are comfortable and satisfied in spending money to buy our products.

$4 \quad$ Our company has a good reputation for our products.

5 We able to satisfy our customers much better than main competitors.

Operational Performance SD D $\quad$ N $\quad$ A $\quad$ SA

1 We can quickly modify products to fulfil customers' needs.

2 We can quickly respond to demand fluctuations.

3 Our customers are satisfied with timely delivery.

$4 \quad$ The waiting time (fromthe order until delivery) is short.

5 At our company, customer service quality is high.

6 Our operational performance is better than the performance of main competitors in the industry.

\section{Appendix B. Regression Standardized Residuals}

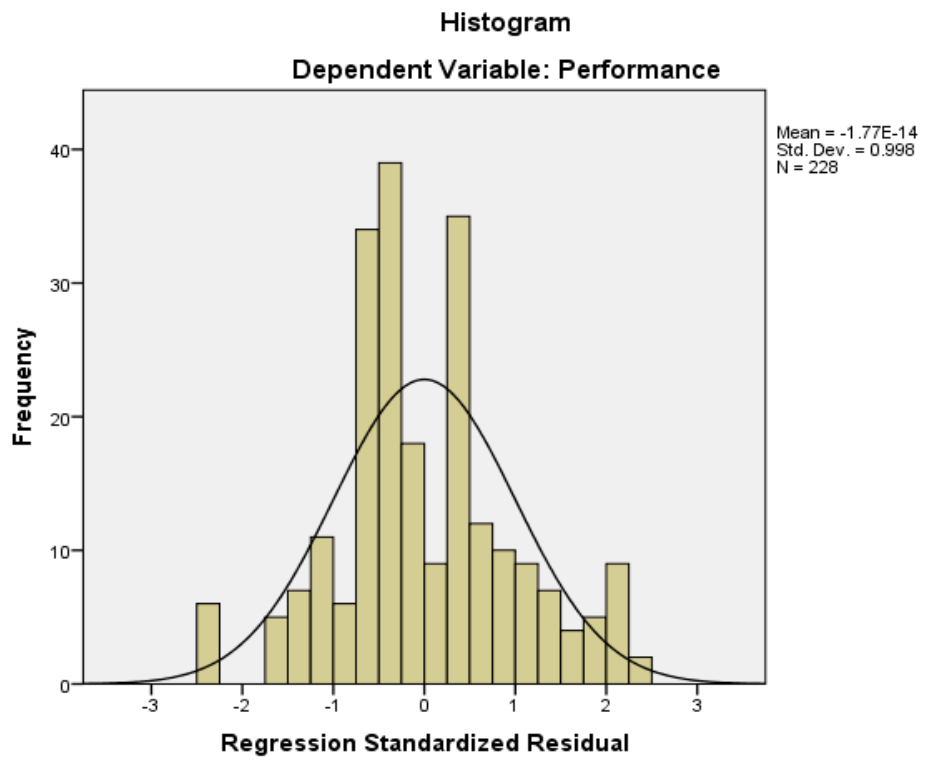




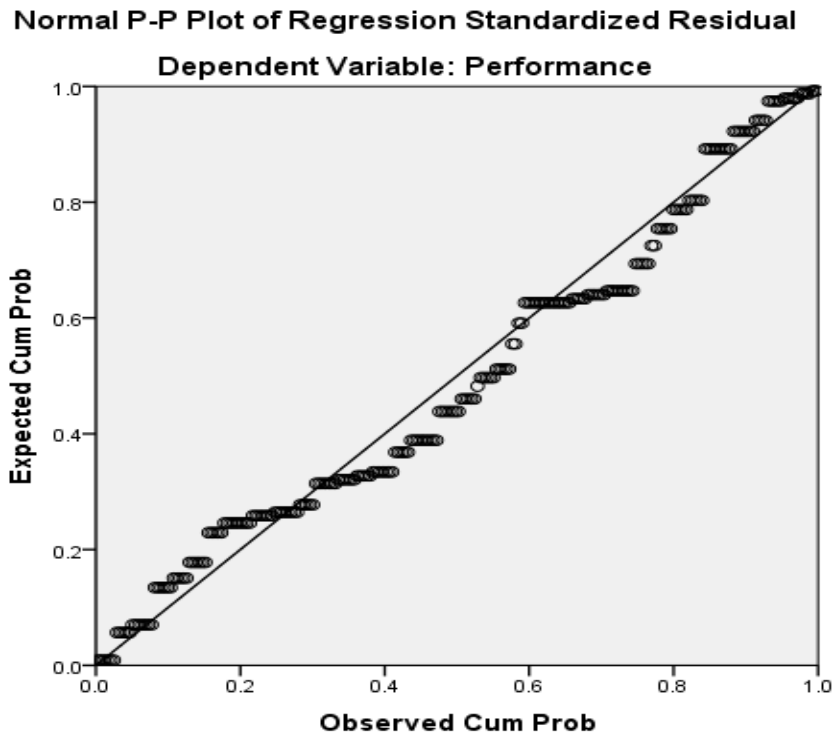

\section{References}

1. Ross, E.A. Uncertainty as a Factor in Production. Ann. Am. Acad. Political Soc. Sci. 1896, 8, 92-119. [CrossRef]

2. DiFonzo, N. Corporate rumour activity, belief and accuracy. Public Relat. Rev. 2002, 28, 1-19. [CrossRef]

3. Bendickson, J.; Gur, F.A.; Taylor, E.C. Reducing environmental uncertainty: How high performance work systems moderate the resource dependence-firm performance relationship. Can. J. Adm. Sci. Rev. Can. Des Sci. De L'Administration 2018, 35, $252-264$. [CrossRef]

4. Kaňovská, L.; Bumberová, V. The Differences in the Propensity of Providing Smart Services by SMEs from the Electrical Engineering Industry with Regard to Their Cooperation and Innovation Flexibility. Sustainability 2021, 13, 5008. [CrossRef]

5. Nair, A. Linking manufacturing postponement, centralized distribution and value chain flexibility with performance. Int. J. Prod. Res. 2005, 43, 447-463. [CrossRef]

6. Lübke, L.; Pinquart, M.; Schwinger, M. The Role of Flexibility in the Realization of Inclusive Education. Sustainability 2021, 13, 4452. [CrossRef]

7. Sánchez Martínez, A.; Pérez, M. Supply chain flexibility and firm performance: A conceptual model and empirical study in the automotive industry. Int. J. Oper. Prod. Manag. 2005, 25, 681-700. [CrossRef]

8. Ni, G.; Xu, H.; Cui, Q.; Qiao, Y.; Zhang, Z.; Li, H.; Hickey, P.J. Influence Mechanism of Organizational Flexibility on Enterprise Competitiveness: The Mediating Role of Organizational Innovation. Sustainability 2021, 13, 176. [CrossRef]

9. Archer, N.P.; Kumar, V.; Fantazy, K.A.; Kumar, U.; Boyle, T.A. Implementation and management framework for supply chain flexibility. J. Enterp. Inf. Manag. 2006, 19, 303-319. [CrossRef]

10. Delbart, T.; Molenbruch, Y.; Braekers, K.; Caris, A. Uncertainty in Intermodal and Synchromodal Transport: Review and Future Research Directions. Sustainability 2021, 13, 3980. [CrossRef]

11. Karsili, H.; Yesiltas, M.; Berberoglu, A. Workplace Flexibility for Sustainable Career Satisfaction: Case of Handling in the Aviation Sector in North Cyprus. Sustainability 2021, 13, 6878. [CrossRef]

12. Merschmann, U.; Thonemann, U.W. Supply chain flexibility, uncertainty and firm performance: An empirical analysis of German manufacturing firms. Int. J. Prod. Econ. 2011, 130, 43-53. [CrossRef]

13. Vickery, S.N.; Calantone, R.; Dröge, C. Supply chain flexibility: An empirical study. J. Supply Chain. Manag. 1999, 35, 16-24. [CrossRef]

14. Lummus, R.R.; Vokurka, R.J.; Duclos, L.K. Delphi study on supply chain flexibility. Int. J. Prod. Res. 2005, 43, 2687-2708. [CrossRef]

15. Camisón, C.; VillarLópez, A. An examination of the relationship between manufacturing flexibility and firm performance: The mediating role of innovation. Int. J. Oper. Prod. Manag. 2010, 30, 853-878. [CrossRef]

16. Sáenz, M.J.; Knoppen, D.; Tachizawa, E.M. Building manufacturing flexibility with strategic suppliers and contingent effect of product dynamism on customer satisfaction. J. Purch. supply Manag. 2018, 24, 238-246. [CrossRef]

17. Narasimhan, R.; Talluri, S.; Das, A. Exploring flexibility and execution competencies of manufacturing firms. J. Oper. Manag. 2004, 22, 91-106. [CrossRef]

18. Upton, D.M. The management of manufacturing flexibility. Calif. Manag. Rev. 1994, 36, 72-89. [CrossRef]

19. Yuan, L.; Zhongfeng, S.; Yi, L. Can strategic flexibility help firms profit from product innovation? Technovation 2010, 30, 300-309. [CrossRef]

20. Shabaninejad, H.; Yusefzadeh, H.; Mehralian, G.; Rahimi, B. The structure of the world pharmaceutical market: Prioritizing Iran's target export markets. Iran. J. Pharm. Res. 2019, 18, 546-555. [CrossRef] 
21. Gaimon, C.; Singhal, V. Flexibility and the choice of manufacturing facilities under short product life cycles. Eur. J. Oper. Res. 1992, 60, 211-223. [CrossRef]

22. Chod, J.; Rudi, N. Resource flexibility with responsive pricing. Oper. Res. 2005, 53, 532-548. [CrossRef]

23. Fawcett, S.E.; Magnan, G.M.; McCarter, M.W. Benefits, barriers, and bridges to effective supply chain management. Supplychain Manag. 2008, 13, 35-48. [CrossRef]

24. Fynes, B.; De Búrca, S.; Marshall, D. Environmental uncertainty, supply chain relationship quality and performance. J. Purch. Supply Manag. 2004, 10, 179-190. [CrossRef]

25. Bamel, U.K.; Bamel, N. Organizational resources, KM process capability and strategic flexibility: A dynamic resource-capability perspective. J. Knowl. Manag. 2018, 7, 1555-1572. [CrossRef]

26. Sanchez, R. Strategic flexibility in product competition. Strateg. Manag. J. 1995, 16, 135-159. [CrossRef]

27. Auh, S.; Menguc, B. Balancing exploration and exploitation: The moderating role of competitive intensity. J. Bus. Res. 2005, 58, 1652-1661. [CrossRef]

28. Barney, J.B. Firm resources and sustained competitive advantage. J. Manag. 1991, 17, 99-120. [CrossRef]

29. Tajeddini, K.; Altinay, L.; Ratten, V. Service innovativeness and the structuring of organizations: The moderating roles of learning orientation and inter-functional coordination. Int. J. Hosp. Manag. 2017, 65, 100-114. [CrossRef]

30. Chan, A.T.; Ngai, E.W.; Moon, K.K. The effects of strategic and manufacturing flexibilities and supply chain agility on firm performance in the fashion industry. Eur. J. Oper. Res. 2017, 259, 486-499. [CrossRef]

31. Cetindamar, D.; Phaal, R.; Probert, D. Understanding technology management as a dynamic capability: A framework for technology management activities. Technovation 2009, 29, 237-246. [CrossRef]

32. Pondy, L.R.; Mitroff, I.I. Beyond open system models of organization. In Research In Organizational Behaviour, 1st ed.; JAI Press: Greenwich, CT, USA, 1979; pp. 3-39; ISBN 0-89232-045-1.

33. Hill, T.; Chambers, S. Flexibility-a manufacturing conundrum. Int. J. Oper. Prod. Manag. 1991, 11, 5-13. [CrossRef]

34. Xu, M.; Lu, Y. The effect of supply uncertainty in price-setting newsvendor models. Eur. J. Oper. Res. 2013, 227, 423-433. [CrossRef]

35. Hu, B.; Feng, Y. Optimization and coordination of supply chain with revenue sharing contracts and service requirement under supply and demand uncertainty. Int. J. Prod. Econ. 2017, 183, 185-193. [CrossRef]

36. Walker, G.; Weber, D. Supplier competition, uncertainty, and make-or-buy decisions. Acad. Manag. J. 1987, 30, 589-596. [CrossRef]

37. Huang, S.-M.; Ou, C.-S.; Chen, C.M.; Lin, B. An empirical study of relationship between IT investment and firm performance: A resource-based perspective. Eur. J. Oper. Res. 2006, 173, 984-999. [CrossRef]

38. Nadkarni, S.; Narayanan, V.K. Strategic schemas, strategic flexibility, and firm performance: The moderating role of industry clockspeed. Strateg. Manag. J. 2007, 28, 243-270. [CrossRef]

39. Lau, C.M.; Sholihin, M. Financial and nonfinancial performance measures: How do they affect job satisfaction? Br. Account. Rev. 2005, 37, 389-413. [CrossRef]

40. Ittner, C.D.; Larcker, D.F. Are nonfinancial measures leading indicators of financial performance? An analysis of customer satisfaction. J. Account. Res. 1998, 36, 1-35. [CrossRef]

41. Malagueño, R.; Lopez-Valeiras, E.; Gomez-Conde, J. Balanced scorecard in SMEs: Effects on innovation and financial performance. Small Bus. Econ. 2018, 51, 221-244. [CrossRef]

42. Hauser, J.R.; Simester, D.I.; Wernerfelt, B. Customer satisfaction incentives. Mark. Sci. 1994, 13, 327-423. [CrossRef]

43. Hayes, A.F.; Montoya, A.K.; Rockwood, N.J. The analysis of mechanisms and their contingencies: PROCESS versus structural equation modeling. Australas. Mark. J. 2017, 25, 76-81. [CrossRef]

44. Tavakol, M.; Dennick, R. Making sense of Cronbach's alpha. Int. J. Med. Educ. 2011, 2, 53-64. [CrossRef] 